\title{
Mass spectrometry screening of Arabica coffee roasting: A non-target and non-volatile approach by EASI-MS and ESI-MS
}

\author{
Jeane Santos da Rosa ${ }^{\mathrm{a}, \mathrm{b}, *}$, Otniel Freitas-Silva ${ }^{\mathrm{a}}$, Janaina Ribeiro Costa Rouws ${ }^{\mathrm{c}}$, Iris Gonçalves da Silva Moreira ${ }^{\mathrm{b}}$, \\ Fabio Junior Moreira Novaes ${ }^{b}$, Débora de Almeida Azevedo ${ }^{b}$, Nicolas Schwab ${ }^{\mathrm{d}}$, Ronoel Luiz de Oliveira Godoy ${ }^{\mathrm{a}}$, \\ Marcos Nogueira Eberlin ${ }^{\mathrm{d}}$, Claudia Moraes de Rezende ${ }^{\mathrm{b}, *}$ \\ a Embrapa Food Technology, Avenida das Américas, 29501 Rio de Janeiro, RJ, Brazil \\ ${ }^{\mathrm{b}}$ Federal University of Rio de Janeiro (UFRJ), Institute of Chemistry, Avenida Athos da Silveira Ramos, 149 Rio de Janeiro, RJ, Brazil \\ c Embrapa Agrobiology, BR-465, KM7, Ecologia, Seropédica, RJ, Brazil \\ d ThoMSon Mass Spectrometry Laboratory, Institute of Chemistry, University of Campinas (UNICAMP), Rua Josué de Castro 126, Cidade Universitária, Campinas, SP, Brazil
}

\section{A R T I C L E I N F O}

\section{Article history:}

Received 31 October 2015

Received in revised form 5 March 2016

Accepted 8 March 2016

Available online 11 March 2016

\section{Keywords:}

Tryptamides

Fluorescence

Ambient mass spectrometry

Diacylglycerols

Triacylglycerols

High resolution mass spectrometry

Roast consistency

\begin{abstract}
A B S T R A C T
Coffee roasting needs precise control and innovative techniques that are economically viable to monitor and improve its consistency. In this study, mass spectrometry was used as a tool to screen chemical markers that appear on the surface of coffee beans (whole bean) along the roasting process. A non-target and non-volatile approach was used with an ambient technique (EASI) coupled to a single quadrupole mass analyzer to monitor roasting chemical changes in the coffee bean. Green (raw), soft, medium, dark and very dark roasted coffee beans showed a decrease in ions in the range of $m / z 500-600$, whereas an increase in abundance in the $m / z$ 800-900 range was clearly observed in the most roasted coffees. A multivariate approach through PCA separated the different roasts in $70 \%$ of the variance using PC1 and PC2. The major ions in the range of $m / z$ 500-600 were characterized by ESI-MS and also HPLC-fluorescence as the $N$-alkanoyltryptamides, surface constituents of coffee wax layer which are almost fully degraded in darker roasts. The ions in the range of $m / z$ 800-900 were characterized as di-and triacylglicerols and its increase during the roasting process was systematically observed. For these classes of chemical markers of the roasting process, ESI-MS showed also the sodium and potassium adducts with good relative abundances.
\end{abstract}

(C) 2016 Elsevier Ltd. All rights reserved.

\section{Introduction}

Coffee is the second global commodity nowadays only behind petroleum and thus plays an important role in world economy. Coffee as a drink is appreciated worldwide and is no longer seen just as a stimulant, but has recognized functional properties and a growing gourmet market. There is a complexity of aromas and flavors in a cup of good quality coffee, which result from the extensive technology employed in planting, harvesting, fruit processing, storing, roasting and even grinding the roasted grain (Dórea \& da Costa, 2005; Esquivel \& Jiménez, 2012).

From the food processing point of view, coffee roasting consists of a transfer of mass triggered by heating and the consequent endothermic and exothermic reactions. In general, coffee beans are roasted using hot combustion gases that heat the roaster drum (conduction) or hot air (convection) at temperatures that can reach up to $250^{\circ} \mathrm{C}$ (Bottazzi, Farina, Milani, \& Montorsi, 2012).

The roasted coffee bean has a peculiar shape and its structure is heterogeneous. On heating, its volume swells and the inner structure

\footnotetext{
* Corresponding authors.

E-mail addresses: jeane.rosa@embrapa.br (J.S. Rosa), crezende@iq.ufrj.br (C.M. Rezende).
}

collapses, releasing cell contents. The increase in the bean size, number and size of pores and internal cavities and the decrease in weight and density are due to the amount of steam and $\mathrm{CO}_{2}$ released during the process. Carbon dioxide is the main gas produced during roasting. The $\mathrm{CO}_{2}$ comes from sugar pyrolysis and secondary reactions from the Maillard reaction. The inside amount of $\mathrm{CO}_{2}$ is also responsible for the extended shelf life of coffee beans until grinding (Wang \& Lim, 2015).

A brief literature review on studies of roasting consistency, reproducibility and quality shows there is a focus on volatile organic compounds (VOCs) or target analytes, mainly caffeine, chlorogenic acids, trigonelline, kahweol and cafestol (kaurene diterpenes) and some sugars. Most of these studies use rapid analytical techniques that are less time consuming in sample preparation, but require more complex analytical systems as mass spectrometry, soft ionization sources that are often employed to provide mass spectra that closely represent the molecular information with low fragmentation. In the same way the use of multivariate analysis techniques such as the Principal Component Analysis (PCA) is almost mandatory (Amorim et al., 2009; Hertz-Schünemann, Dorfner, Yeretzian, Streibel, \& Zimmermann, 2013; Wieland et al., 2012).

Ambient ionization MS consists of several techniques that are gaining attention in the scientific community due to simplicity of operation and free sample preparation practicality. DESI (Desorption 


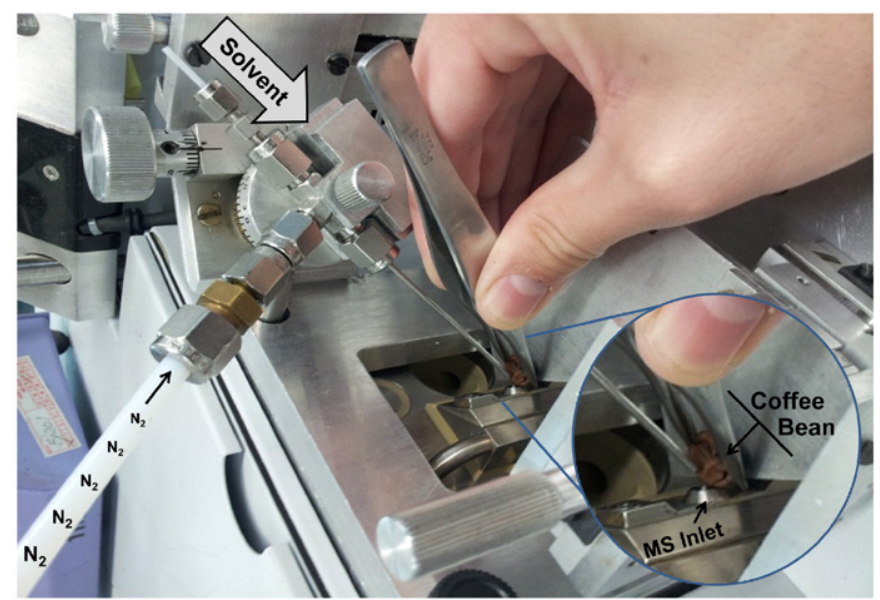

Fig. 1. EASI-MS experiment. Ten beans per sample were taken and evaluated randomly.

Electrospray) in 2004 and DART (Direct Analysis in Real Time) in 2005 started this new age in mass spectrometry analysis (Cody, Laramée, \& Durst, 2005; Cooks, Ouyang, Takats, \& Wiseman, 2006). These ambient techniques basically produce a flow of ions directly from the sample under investigation to the mass analyzer, requiring no vacuum or special chambers containing a high gas flow. In fact, its principal advantage is the direct analysis with practically no sample preparation. Huang,
Cheng, Cho, and Shiea (2011) presented a very logical and simple approach to the classification of ambient source techniques based on their ionization principles. Thus, three major groups of techniques that lead to the production of ions from target analytes were established: a) direct ionization technique, b) direct desorption/ionization techniques and c) two-step ionization techniques.

In the direct ionization techniques a high electric field induces an electrospray ionization from an analyte solution, solid or droplet. In the direct desorption/ionization techniques, the sample surface suffers an impact of species such as charged solvent droplets, ions and metastable gases. The analyte molecules are then desorbed and ionized from the sample surface. In the two-step ionization techniques, there is first the formation of charged species such as solvents, ions and metastable gases and the formation of analytes of interest through laser irradiation, thermal energy, shock waves or nebulization. The analytes then react with the charged species or metastable gases, producing analyte ions.

The EASI source used in this work is one of the milder ionizations available nowadays and is a direct desorption/ionization technique that uses a voltage-free apparatus (Haddad, Sparrapan, \& Eberlin, 2006). EASI hardware is simple and inexpensive as is made up of a Swagelok T-connector, fittings, a fused silica capillary at the solvent entrance and a stainless steel duct at the exit to the sample where nebulization occurs (Fig. 1). No voltage or high temperatures are used and the high-velocity sprayer from nitrogen and charged solvent produce small charged droplets. Soft ionization occurs due to a random distribution of positive/ negative ions in such droplets (Harris, Galhena, \& Fernandez, 2011).
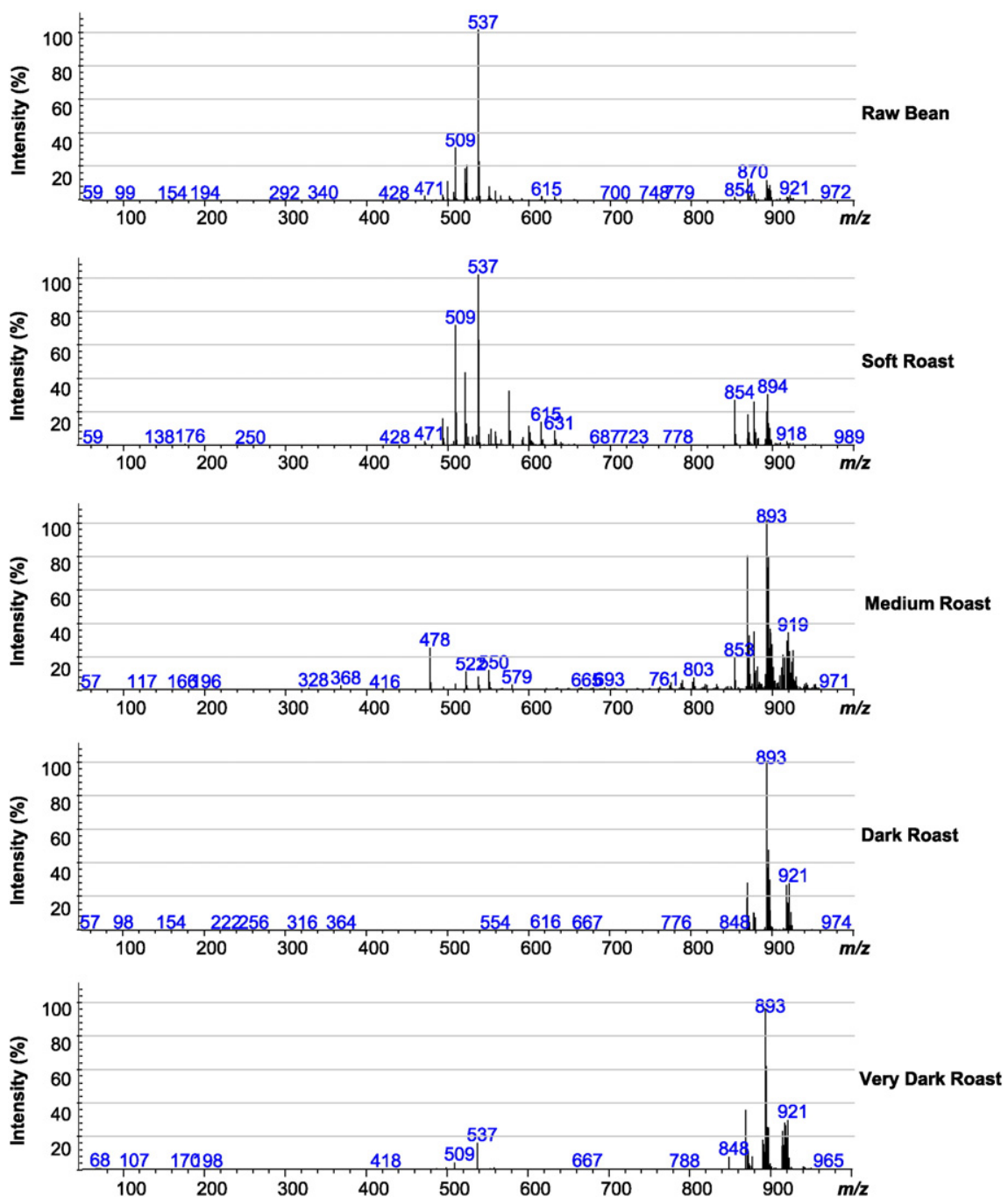

Fig. 2. Mass spectra of beans from Sample 9: green beans (raw), soft, medium, dark and very dark roasts from an EASI-MS experiment in positive ionization mode: EASI(+) -MS. 
The aim of this study was to employ non-target compounds techniques to monitor changes in coffee bean surfaces during roasting, using rapid and direct methods in a "press button" way. The goals were to identify roasting levels of the studied samples, establishing a chemical fingerprint of the roast degree and its chemical markers through EASI-MS, and to monitor and suggest the identification of the possible chemical markers by ESI-MS-, using the exact mass of information as the guide.

\section{Material and methods}

\subsection{Coffee blends and roasting process}

Three Arabica coffee samples from the South of Minas Gerais state in Brazil were roasted at light, medium, dark and very dark levels. The samples were donated by Minas Sul coffee producer cooperative and were from plants growing at medium/high altitudes ( 800 to $1400 \mathrm{~m}$ ), all the plants were Coffea arabica L. cultivars Mundo Novo, Catuaí and Bourbon. The samples were from the 2011 harvest.

The roasting of the samples was performed in a semi industrial roaster at Grão Mestre Café, a training center run by ABIC (Brazilian Association of Coffee Industries). The roasting process was operatordependent as in the industry. The three coffee blends were identified by their levels of defective beans (50, 15 and 9). Thus, 15 samples were generated after roasting these three samples at the four roasting levels (light to very dark) plus green (raw) beans.

In order to eliminate possible effects of the defective beans, they were removed generating clean samples that were identified as: 050, 015 and 09. All defective beans removed from the samples also made a sample, a pool of defective beans, identified as sample 100. In this way, after roasting at the four levels plus raw beans, twenty new samples were generated. Thus, there were a total of 35 samples evaluated

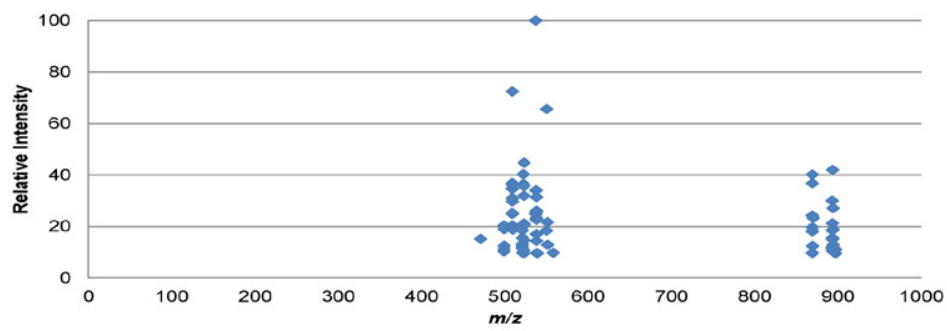

Raw Beans

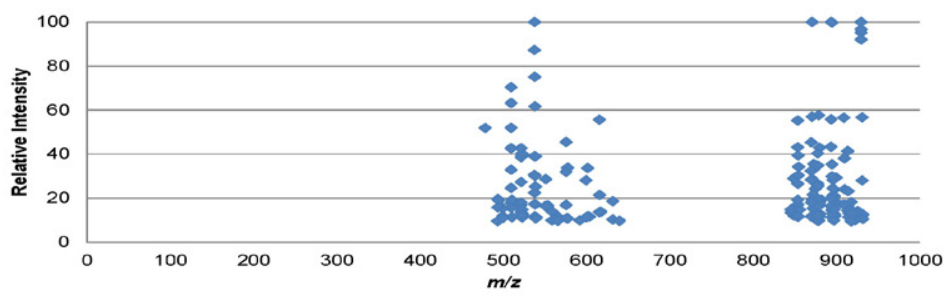

Soft Roast

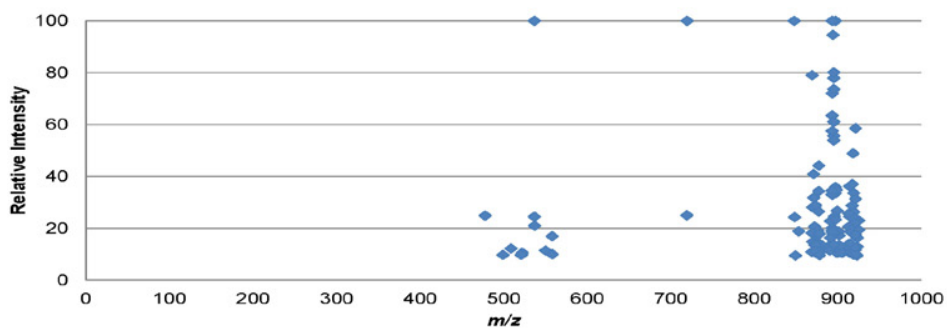

Medium

Roast

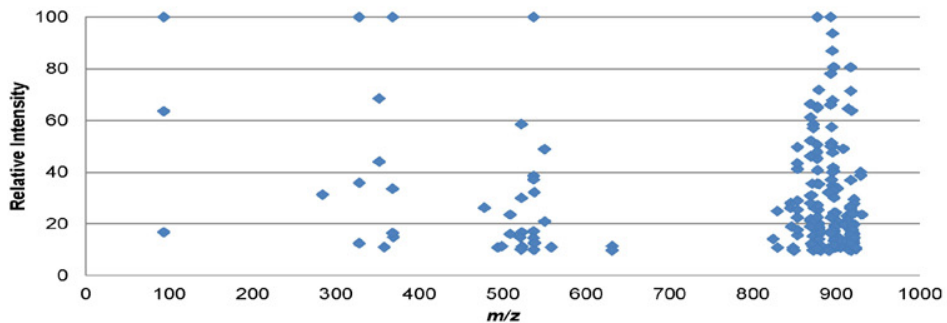

Dark Roast

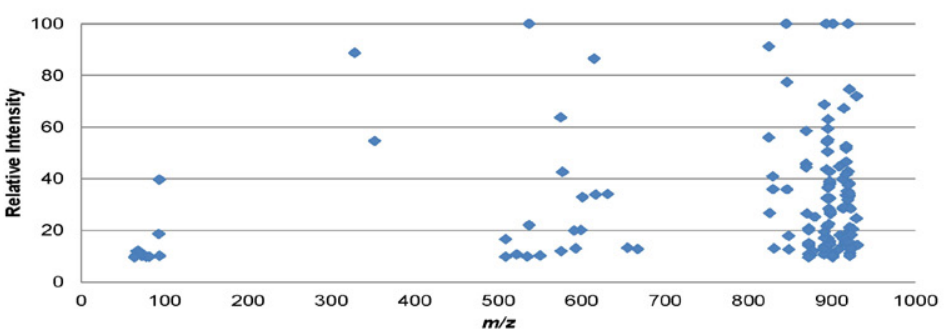

Very Dark

Roast

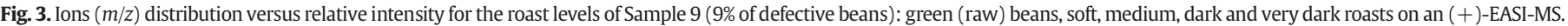




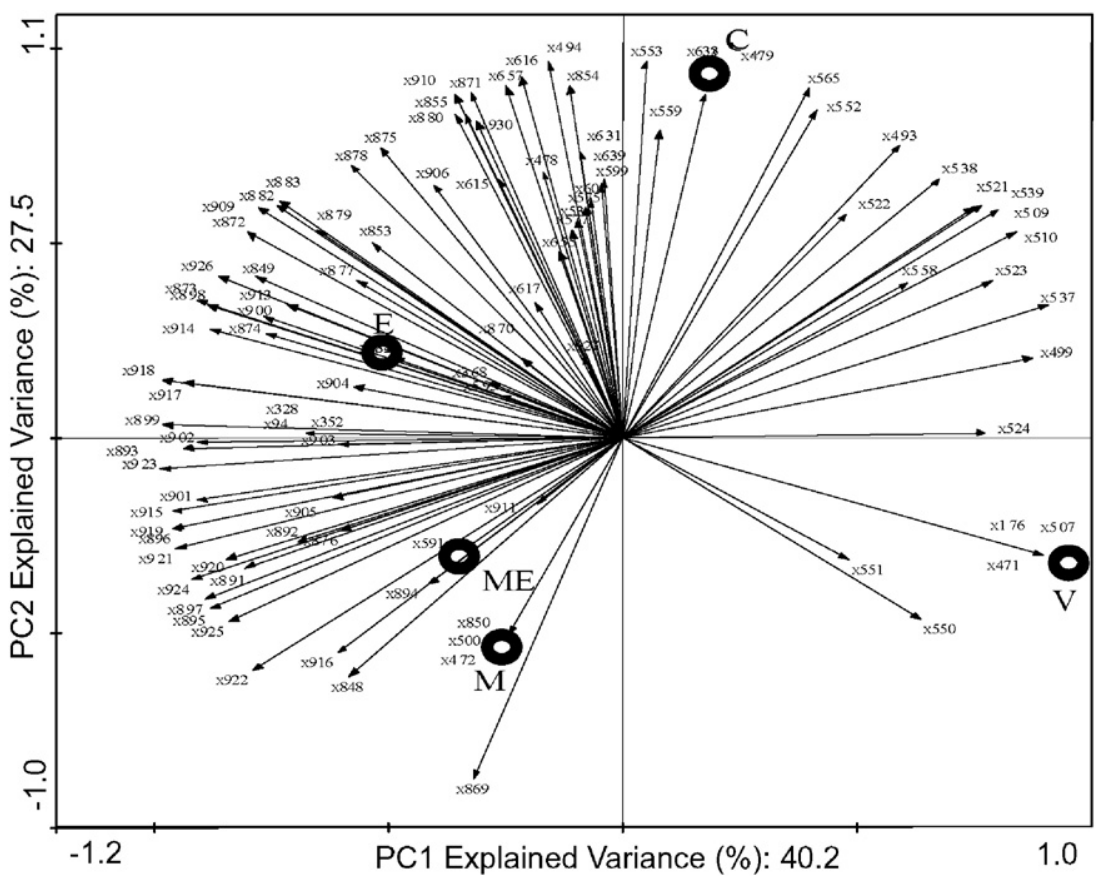

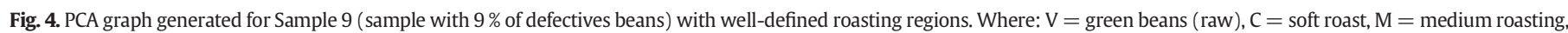
$\mathrm{E}=$ dark roast and $\mathrm{ME}=$ very dark roasting. $\mathrm{PC} 1 \times \mathrm{PC} 2$ graphs for the other samples are in the Supplementary material.

by this study. The samples were: $9,09,15,015,50,050$ and 100 each one with four roasting levels and its green beans (raw). Approximately $500 \mathrm{~g}$ of each coffee sample were roasted to the four desired levels. The samples were kept in the dark wrapped in plastic bags.

\subsection{Screenings}

To establish the roast level and fingerprinting of the roast markers, beans from each sample were placed in front of the mass analyzer entrance, generating mass spectra. The EASI source, operating in the positive mode, was from the the ThoMSon Laboratory, Institute of Chemistry at the University of Campinas and the mass spectrometer was a single quadrupole Shimadzu model 2010A. The coffee bean samples were analyzed by positioning them between the EASI source jet (methanol/formic acid (1\%) under a perpendicular high flow of nitrogen) and the entrance of the mass analyzer.

Ten beans from each sample were evaluated generating three hundred and fifty mass spectra from the bean surfaces. No repetitions were performed for individual bean, but ten different beans per sample were taken and evaluated randomly. This was the maximum number of evaluations possible due to equipment availability. The data were displayed on an Excel ${ }^{\circledR}$ spreadsheet where one hundred and ten significant ions were tabled as variables and their relative abundances. The data were transferred to the Canoco ${ }^{\circledR}$ program version 4.5 for multivariate analysis. The samples were evaluated separately on their corresponding degrees of roast and defective beans effects were not considered in this study.

\subsection{ESI-MS screenings}

In order to identify the chemical markers of the roasting levels, screening experiments on ESI-QTOF were performed with $1 \mathrm{~g}$ of whole beans. The extracts were made in an ultrasound bath for $1 \mathrm{~min}$ with a solution of methanol and $0.1 \%$ formic acid $(5 \mathrm{~mL})$. A QTOF Waters Synapt ${ }^{\circledR}$ G1 mass spectrometer was used mainly in ESI $(+)$. The experimental conditions were: capillary temperature: $150{ }^{\circ} \mathrm{C}$; desolvation: $40{ }^{\circ} \mathrm{C}$; capillary energy $3.0 \mathrm{kV}$; cone: $22 \mathrm{~V}$; cone extraction: $7.0 \mathrm{~V}$; $\mathrm{N}_{2}$ flow: cone: $60 \mathrm{~mL} / \mathrm{min}$; desolvation: $300 \mathrm{~mL} / \mathrm{min}$ and default energy in collision cell. Screenings were performed for $5 \mathrm{~min}$ in the direct infusion mode.

\subsection{HPLC fluorescence (FLD) and diode array (PDA) analysis of the $\mathrm{N}$-alcanoyl-5-hydroxytryptamides}

A HPLC fluorescence (FLD) and a diode array detector (PDA) method were also developed to qualify tryptamide derivatives in the samples. Using the same sample extraction method as for the QTOF screening,

Table 1

Relevant ions found by $(+)$ EASI-MS for the different roast degrees of each studied samples.

\begin{tabular}{|c|c|c|c|c|c|}
\hline \multirow{2}{*}{ Sample } & \multicolumn{5}{|l|}{ Roast degree } \\
\hline & Green & Soft & Medium & Dark & Very dark \\
\hline 9 & 537 & $553,493,615,853,657$ & 593,615 & $923,893,917,901,869$ & $869^{\mathrm{a}}$ \\
\hline 09 & $521,537,493,509,551,499$ & $471^{\mathrm{a}}$ & 284 & $923^{\mathrm{a}}$ & $893,877,919,898,853$ \\
\hline 15 & $649,521,615,631,493,655$ & $849,853,877,899$ & $921^{\mathrm{a}}$ & $902,913,877$ & 896 \\
\hline 015 & $537,509,553$ & $558,575,615,599,848,903,871$ & $893,919,94,915$ & $923^{\mathrm{a}}, 911^{\mathrm{a}}$ & 923 \\
\hline 50 & $649,639,591,577,559,521,509,499,617,369$ & $916,912,899,927$ & $869^{\mathrm{a}}$ & $923^{\mathrm{a}}, 877^{\mathrm{a}}, 893^{\mathrm{a}}$ & 925 \\
\hline 050 & $655,631,176,521,537$ & $561^{\mathrm{a}}$ & 537,575 & $877^{\mathrm{a}}, 893^{\mathrm{a}}, 869^{\mathrm{a}}, 918^{\mathrm{a}}$ & 869,479 \\
\hline 100 & 537 & $930^{\mathrm{a}}, 593^{\mathrm{a}}, 284^{\mathrm{a}}, 911^{\mathrm{a}}$ & 853 & 558,104 & $896,873,923$ \\
\hline
\end{tabular}

\footnotetext{
a Ions in PC3 and PC4.
} 

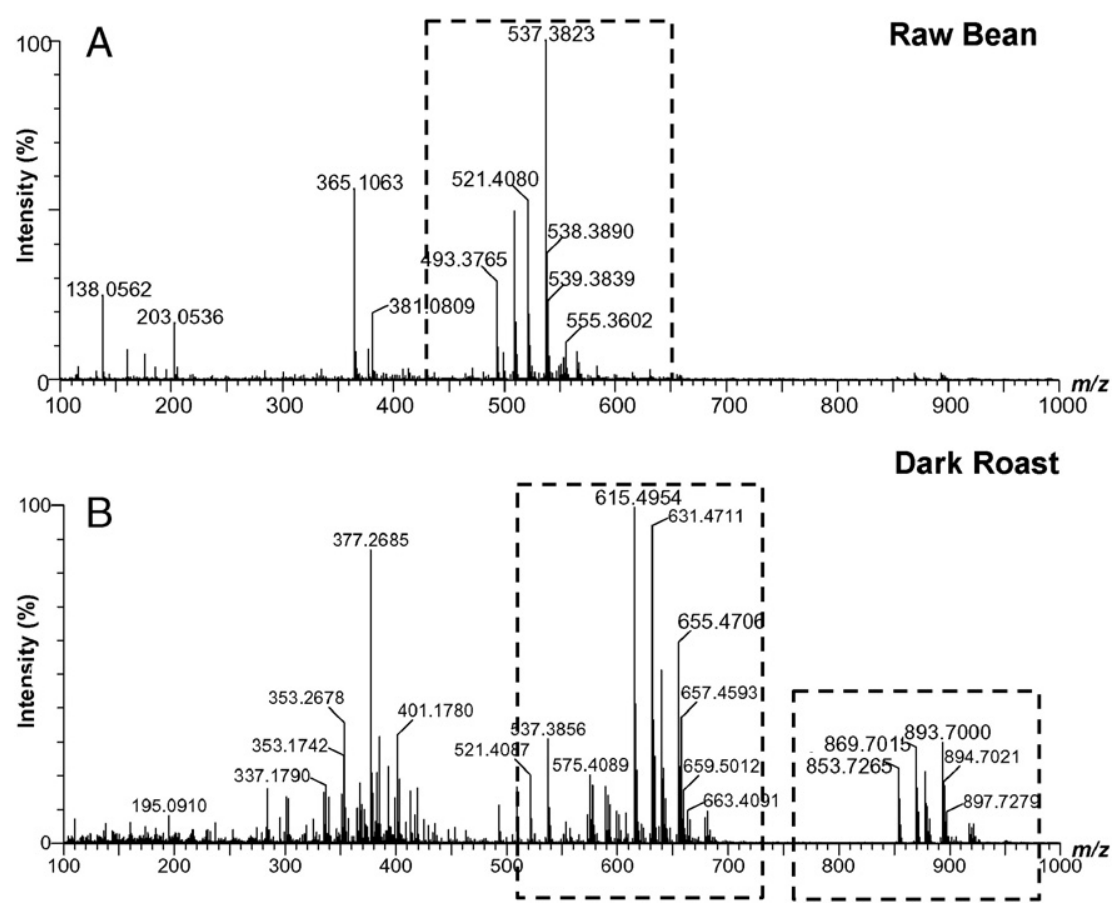

Fig. 5. ESI (+) QTOF spectra of raw (A) and very dark (B) methanolic extracts of the whole coffee bean in dark roast.

samples were injected into a Liquid Chromatograph Waters Alliance ${ }^{\circledR}$ e2695 equipped with a Waters 2475 fluorescence detector ( $E X=$ $280 \mathrm{~nm}$ and $\mathrm{EM}=340 \mathrm{~nm}$ ). Excitation and emission wavelengths were based on serotonin spectra. Waters 2998 PDA detector was used separately. The standards of $\mathrm{C}_{14}, \mathrm{C}_{16}, \mathrm{C}_{18}$ and $\mathrm{C}_{20} 5 \mathrm{HT}$ were previously synthetized in the Aroma Laboratory of Federal University of Rio de Janeiro (Lang et al., 2009)). A Thermo C18 column $5 \mathrm{~cm} \times 4.6 \mathrm{~mm}$ and $2.6 \mu \mathrm{m}$ was used. The injection volume was of $1 \mu \mathrm{L}$. A linear gradient was performed with methanol/formic acid of $1 \%$. The initial composition $27 / 63$ changed to $100 / 0$ in 15 min and stayed in this proportion for $25 \mathrm{~min}$. After $30 \mathrm{~min}$ the composition returned to the initial conditions.

\section{Results and discussion}

3.1. Fingerprinting and ion markers of roasting degree from EASI-MS screenings

EASI-MS experiment in a coffee bean surface is shown in Fig. 1 and produced spectra such as the ones showed in Fig. 2. These spectra are from green (raw), soft, medium, dark and very dark roastings and from sample 9 ( $9 \%$ of defective beans) and shows that an increase in roasting degree decreases ions in the $m / z$ 500-600 range whereas increasing ions in the range of $m / z 800-900$.

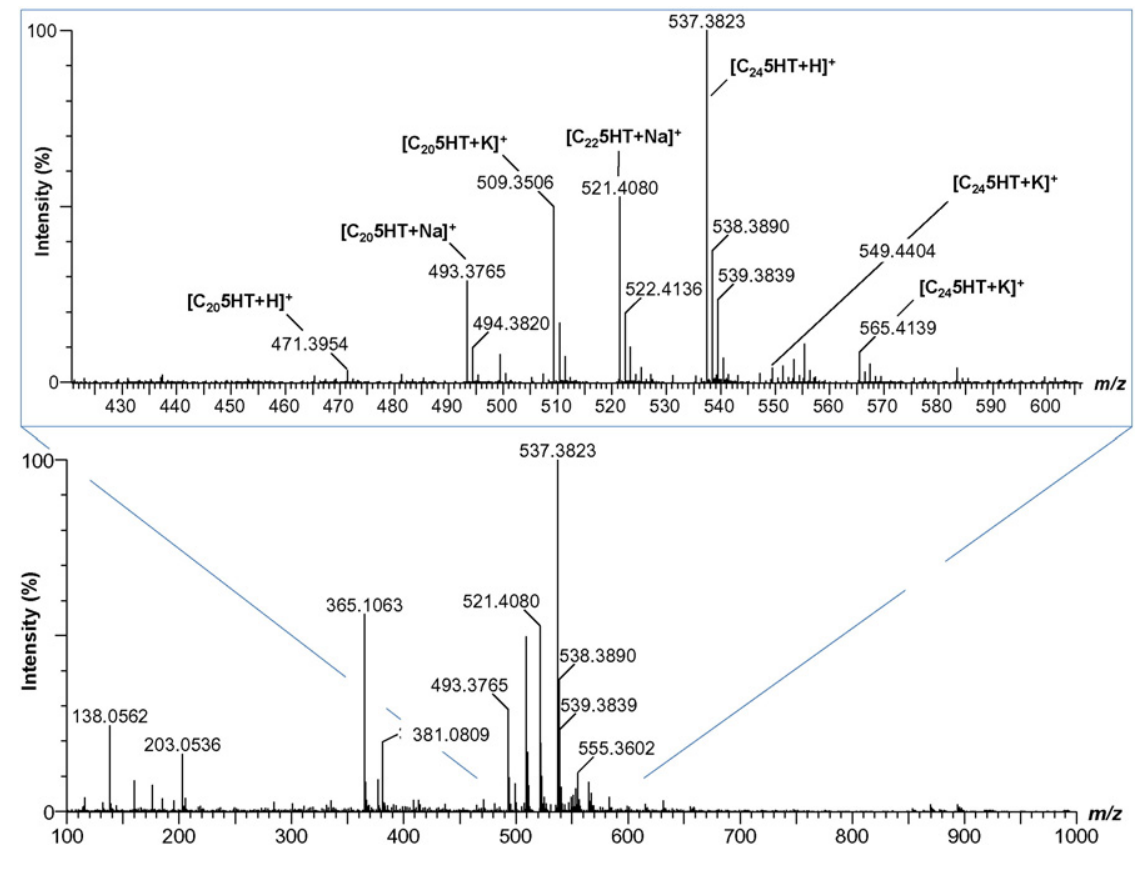

Fig. 6. Zoom in the region of tryptamides on a ESI spectrum of raw beans. 
Fig. 3 shows the ions $(\mathrm{m} / \mathrm{z})$ versus relative intensity variation in Sample 9 at their levels of roast: green beans (raw), soft, medium, dark and very dark. Each sample represents spectra of 10 beans. This univariate evaluation confirms the tendency of the two major ions groups mentioned above along the roast levels.

A multivariate approach through Principal Component Analysis (PCA) was used to reduce the large number of variables and evaluate the separation of roasting patterns from relevant ions formed on the surface of the coffee beans. Ion peaks with relative intensity below 5\% in a sample were considered as noise for the study and were therefore discarded. Another exclusion criterion was when an ion was not present in at least 10 of the 350 generated spectra (Amorim et al., 2009).

Separate roasting level patterns between the four types of roasted coffees and green coffee was found in all samples, thus there is a relationship between the principal component 1 (PC1) and principal component 2 (PC2) in the PCA analysis. The variability of relative intensities for each ion peak found in each sample was cumulatively explained with at least $67.3 \%$ for the first two components. The ions loaded in this study can be treated as chemical fingerprints to match ideal/safe coffee roasting levels for the samples studied.

As most of the variance information was found in the first two principal components, the graphs were generated on PC1 and PC2 functions only. Fig. 4 shows an example of the PC $1 \times$ PC2 graph generated for Sample 9 (for the other samples, PC1 $\times$ PC2 graphs are in the Supplementary material), where it is possible to discriminate the roasting level regions and the ions responsible for them. Arrows help show the effect of each ion on the values of the principal components; the greater the length of the arrow the greater the effect. The angles between two arrows indicate the correlation between two ions.

The most relevant ions (in ascending order) per roasting degree for each sample are listed in Table 1 . To achieve more ions in some roasts, information of lower relevance in PC3 and PC4 were used. The ions in PC3 and PC4 regions correspond to the smaller arrows in the graph. The selection of ions was also based on the streamlining of isotopic varieties.

The results confirm that ions in the $m / z 500-600$ range appear mostly in raw (green) beans. In the soft and medium roasts, less of the higher MW species were observed, but they are predominant in the dark and very dark roasts.

\subsection{Chemical markers identified by ESI-MS screenings}

In this study, methanolic extracts of samples were injected directly into an ESI-QTOF high resolution mass analyzer in scan mode. Fig. 5 shows two positive ESI-QTOF spectra of raw (A) and very dark extracts (B). The regions highlighted in the spectra have relatively abundant ions that are not well characterized in the literature by similar techniques. In agreement with our previous reports (Amorim et al., 2009), the mass spectra generated by ESI $(+)$ QTOF showed molecules for coffee matrix such as caffeine $m / z 195(\mathrm{M}+\mathrm{H})^{+}$; trigonelline $m / z 138(\mathrm{M}+\mathrm{H})^{+}$and $m / z 176(\mathrm{M}+\mathrm{K})^{+}$; sucrose $m / z 365(\mathrm{M}+\mathrm{Na})^{+}$and $381(\mathrm{M}+\mathrm{K})^{+}$; chlorogenic acid $m / z 377(\mathrm{M}+\mathrm{Na})^{+}$and $393(\mathrm{M}+\mathrm{K})^{+}$, all related to lower MW fraction.

\subsubsection{Scans in the $m / z$ 400-600 region.}

Fig. 6 shows a zoom-in of the $m / z 400-600$ region in a scan of a sample of raw beans. The scale was changed to the ion of highest abundance in the zoom window. The ions marked correspond to the ions identified by exact mass in this study. It is important to notice that continuous calibration of the TOF analyzer (Lock Spray) was used in exact mass measurements. In this region of the spectra, 5-hydroxytryptamide (C5HT) fatty acid derivatives were seen.

Fig. 7 represents the general chemical structure of these substances. The more intense fatty acid derivatives were: $N$ - $\beta$-arachinoyl-5hydroxytryptamide $\left(\mathrm{C}_{20} 5 \mathrm{HT}\right)$ and $N$ - $\beta$-behenoyl-5-hydroxytryptamide

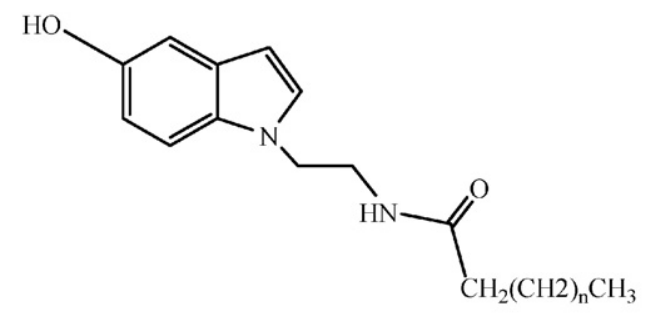

Where: $\begin{array}{r}\mathrm{n}=18 \rightarrow{ }^{\beta} N \text {-arachinoyl-5-hydroxytryptamide }\left(\mathrm{C}_{20} 5 \mathrm{HT}\right) \\ \mathrm{n}=20 \rightarrow{ }^{\beta} N \text {-behenoyl-5-hydroxytryptamide }\left(\mathrm{C}_{22} 5 \mathrm{HT}\right) \\ \mathrm{n}=22 \rightarrow{ }^{\beta} N \text {-lignoceryl-5-hydroxytryptamide }\left(\mathrm{C}_{24} 5 \mathrm{HT}\right)\end{array}$

Fig. 7. General chemical structure of 5-hydroxytryptamide fatty acid derivatives.

$\left(\mathrm{C}_{22} 5 \mathrm{HT}\right)$ of $m / z 471.3954$ and 499.4263 , respectively (Garrett et al., 2014; Speer \& Kölling-Speer, 2006).

Some ions detected in the tryptamide region remained to be identified for all roast levels and in the raw coffee. The ions with greater peak intensity were of $\mathrm{m} / \mathrm{z} 509.3506 ; \mathrm{m} / \mathrm{z} 521.4080$ and $\mathrm{m} / \mathrm{z} 537.3823$ (the most intense of all). Garrett et al. (2014) suggested identification of the ion of $m / z 537$ as a diterpene ester of cafestol (palmitate) obtained by $\left[\mathrm{M}+\mathrm{H}-\mathrm{H}_{2} \mathrm{O}\right]^{+}$. The fragmentation pattern obtained for this same ion in the experiments of this study (data not showed), differs from that found by Garret et al., so it may be another substance.

The ions in the $m / z$ 400-600 range (correlating data with studies from the EASI source) of the roasts studied showed that their peak intensities decreased mainly in the dark and very dark roasts. Despite the discrimination phenomena at the source, this trend may suggest that these analytes are in the wax layer of the bean, partially consumed during the roasting process (Buchmann, Zahm, Kölling-Speer, \& Speer, 2009; Lang et al., 2009).

Fatty acid 5-hydroxy tryptamides $\left(\mathrm{C}_{\mathrm{n}}\right.$ 5HTs $)$ are serotonin derivatives and the principal constituents of coffee wax (a thin outer coating of the bean). Most stomach friendly coffees have had this layer totally removed by dewaxing processes or partially removed by steam treatment because $\mathrm{C}_{\mathrm{n}} 5 \mathrm{HT}$ (besides caffeine, chlorogenic acids and also di/ trihydroxybenzenes from the roasting) can cause irritation in the digestive tract and has an important ulcerogenic potential (Chu, 2012; Farah, 2012). However, $C_{n}$ 5HTs have been the object of important studies for the treatment of Parkinson's disease (Lee et al., 2013). Furthermore, these molecules have an excellent potential to be markers for roasting levels. In fact, the $\mathrm{C}_{\mathrm{n}} 5 \mathrm{HT}$ levels drop by approximately $70 \%$ during the roasting process and are decomposed to serotonin and then to 5hydroxyindole derivatives (Rubach et al., 2014; Zahm \& Speer, 2009).

In Table 2, the principal $m / z$ and molecular formulas founded in this study are listed for the region of Cn5HTs (Couch \& Williams, 1972; Lang et al., 2009; Lang \& Hofmann, 2005).

Potassium adducts have not yet been described for fatty acid tryptamide derivatives. All errors found were well below the $5 \mathrm{ppm}$ limit of the equipment.

Table 2

Identification of the more relevant ions founded in the $m / z 400-600$ for coffee beans.

\begin{tabular}{llcll}
\hline $\begin{array}{l}\text { Experimental } \\
m / z\end{array}$ & $\begin{array}{l}\text { Theoretical } \\
m / z\end{array}$ & $\begin{array}{l}\text { Error } \\
(\mathrm{ppm})\end{array}$ & $\begin{array}{l}\text { Molecular } \\
\text { formula }\end{array}$ & $\begin{array}{l}\text { Suggested } \\
\text { identification }\end{array}$ \\
\hline 471.3954 & 471.3951 & 0.3 & $\mathrm{C}_{30} \mathrm{H}_{50} \mathrm{~N}_{2} \mathrm{O}_{2}$ & $\mathrm{C}_{20} 5 \mathrm{HT}(\mathrm{M}+\mathrm{H})^{+}$ \\
499.4263 & 499.4264 & -0.2 & $\mathrm{C}_{32} \mathrm{H}_{54} \mathrm{~N}_{2} \mathrm{O}_{2}$ & $\mathrm{C}_{22} 5 \mathrm{HT}(\mathrm{M}+\mathrm{H})^{+}$ \\
493.3765 & 493.3770 & -1.0 & $\mathrm{C}_{30} \mathrm{H}_{50} \mathrm{~N}_{2} \mathrm{O}_{2}$ & $\mathrm{C}_{20} 5 \mathrm{HT}(\mathrm{M}+\mathrm{Na})^{+}$ \\
509.3506 & 509.3509 & -0.6 & $\mathrm{C}_{30} \mathrm{H}_{50} \mathrm{~N}_{2} \mathrm{O}_{2}$ & $\mathrm{C}_{20} 5 \mathrm{HT}(\mathrm{M}+\mathrm{K})^{+}$ \\
521.4080 & 521.4083 & -0.6 & $\mathrm{C}_{32} \mathrm{H}_{54} \mathrm{~N}_{2} \mathrm{O}_{2}$ & $\mathrm{C}_{22} 5 \mathrm{HT}(\mathrm{M}+\mathrm{Na})^{+}$ \\
537.3823 & 537.3822 & 0.2 & $\mathrm{C}_{32} \mathrm{H}_{54} \mathrm{~N}_{2} \mathrm{O}_{2}$ & $\mathrm{C}_{22} 5 \mathrm{HT}(\mathrm{M}+\mathrm{K})^{+}$ \\
527.4696 & 527.4577 & -0.2 & $\mathrm{C}_{34} \mathrm{H}_{58} \mathrm{~N}_{2} \mathrm{O}_{2}$ & $\mathrm{C}_{24} 5 \mathrm{HT}(\mathrm{M}+\mathrm{H})^{+}$ \\
549.4404 & 549.4396 & -0.8 & $\mathrm{C}_{34} \mathrm{H}_{58} \mathrm{~N}_{2} \mathrm{O}_{2}$ & $\mathrm{C}_{24} 5 \mathrm{HT}(\mathrm{M}+\mathrm{Na})^{+}$ \\
565.4139 & 565.4135 & -0.4 & $\mathrm{C}_{34} \mathrm{H}_{58} \mathrm{~N}_{2} \mathrm{O}_{2}$ & $\mathrm{C}_{24} 5 \mathrm{HT}(\mathrm{M}+\mathrm{K})^{+}$ \\
\hline
\end{tabular}



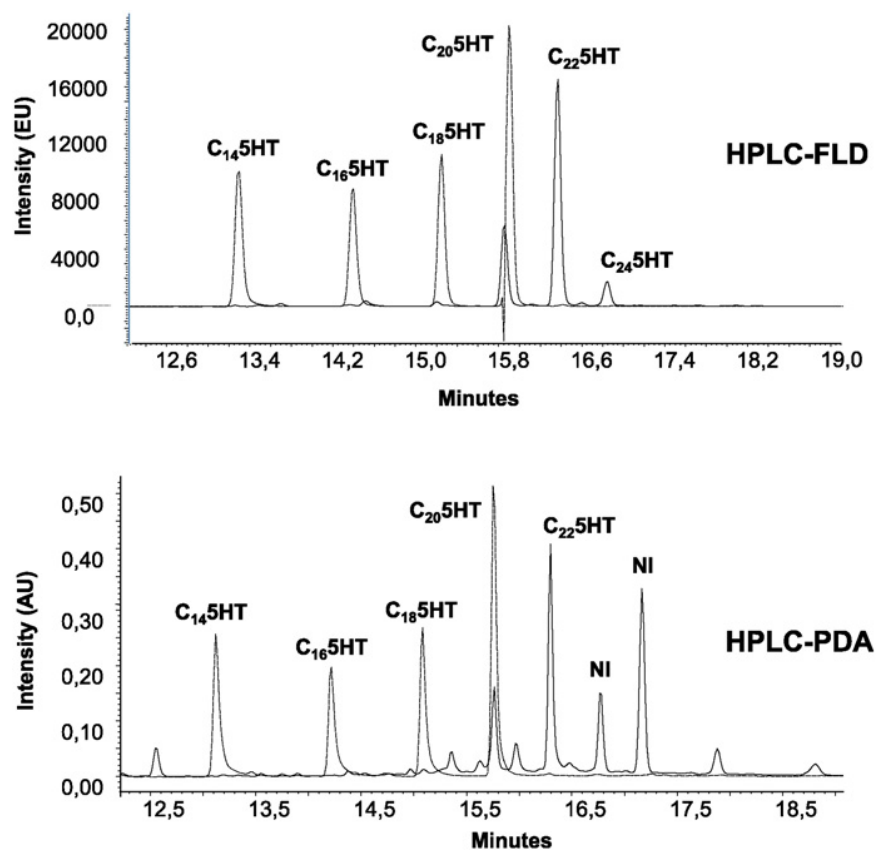

Fig. 8. HPLC chromatograms for FLD and PDA detectors and the qualification of 5hydroxytryptamide fatty acid derivatives in a light roast sample. The dash lines are from standards synthetized in Aroma Laboratory of Federal University of Rio de Janeiro. Where: $\mathrm{NI}=$ not identified.

3.2.2. Verification of 5-hydroxytryptamides fatty acid derivatives by HPLC

Fig. 8 shows the zoomed in and overlay of chromatograms obtained using fluorescence and PDA detectors. The data were not made sequentially. In the fluorescence signal, the dash line is from the tryptamide standards synthetized and the continuous line from an extract of a light roast sample. The spike at the peak of $\mathrm{C}_{20} 5 \mathrm{HT}$ in the standard is due to its higher concentration. The ESI-MS data confirmed the presence of $\mathrm{C}_{22} 5 \mathrm{HT}$ and $\mathrm{C}_{24} 5 \mathrm{HT}$. Cn5HTs were not quantified, but its decrease with elevation of roasting degree was confirmed in the data found by the EASI-MS technique.
In the noisy, less sensitive and less selective PDA signals, there is an overlay between the light roast sample and standard (dash line). In the UV-VIS spectra (in the Supplementary material), it is possible to observe the similarity among $\mathrm{C}_{20} 5 \mathrm{HT}$ profile in standard and in sample. $\mathrm{C}_{22} 5 \mathrm{HT}$ suspect peak in sample also has a similar profile, while $\mathrm{C}_{24} 5 \mathrm{HT}$ could not be observed in the PDA data, probably due to its low concentration. The next relevant vicinal peak has a different spectra profile, and was classified as non-identified (Chattopadhyay, Rukmini, \& Mukherjee, 1996; Martins \& Gloria, 2010).

\subsubsection{Scans in the $m / z 600-800$ region.}

The next important region at the ESI-QTOF mass spectra was from $m / z 600$ to 900, also observed in EASI-MS, is shown in zoom in Fig. 9. Diacylglycerols (DAGs) were identified in A and triacylglycerols (TAGs) in B spectra. Table 3 lists the principal $m / z$ and molecular formulas for these regions of the spectra.

DAGs and TAGs $(\mathrm{M}+\mathrm{H})^{+}$species were not found in the spectra. All $(\mathrm{M}+\mathrm{K})^{+}$ions were more intense than $(\mathrm{M}+\mathrm{Na})^{+}$ions and LL $(\mathrm{M}+\mathrm{Na})^{+}$was the least intense ion among them, which can explain the higher error that still is below $5 \mathrm{ppm}$, the error limit of the equipment.

Segall, Artz, Raslan, Jham, and Takahashi (2005) found thirteen different triacylglycerols in coffee oil. The major ones were PLL (dilinoleoyl-palmitoyl-glycerol - 25.90\%), and PPL (dipalmitoyllinoleoyl-glycerol - 13.74\%) and diacylglycerols. They were observed on $\mathrm{MS}^{2}$ experiments as fragments of TAGs.

Bosco, Toffanin, Palo, Zatti, and Segre (1999) did not find any DAGs in espresso and mocha coffee brews even in strong roasts. Ellis, Brown, in het Panhuis, Blanksby, and Mitchell (2013), reviewed surface MS analysis of lipids and stated that desorption/ionization of TAGs in a DART source resulted in the formation of DAG-like ions, with relative abundance greater than the ions arising from intact TAG molecules, thus making the detection of DAGs originating from tissue matrix difficult.

In this EASI-MS study (a softer ionization source), the samples had been recently roasted and the data showed not only ions in the $m / z$ $600-700$ range, but also in the $m / z$ 800-900 range, which were more intense and representative. In the QTOF screenings, the ESI source temperatures and as well as low CID energies stayed at the minimum levels required by the equipment manufacturer. Therefore, it is believed that

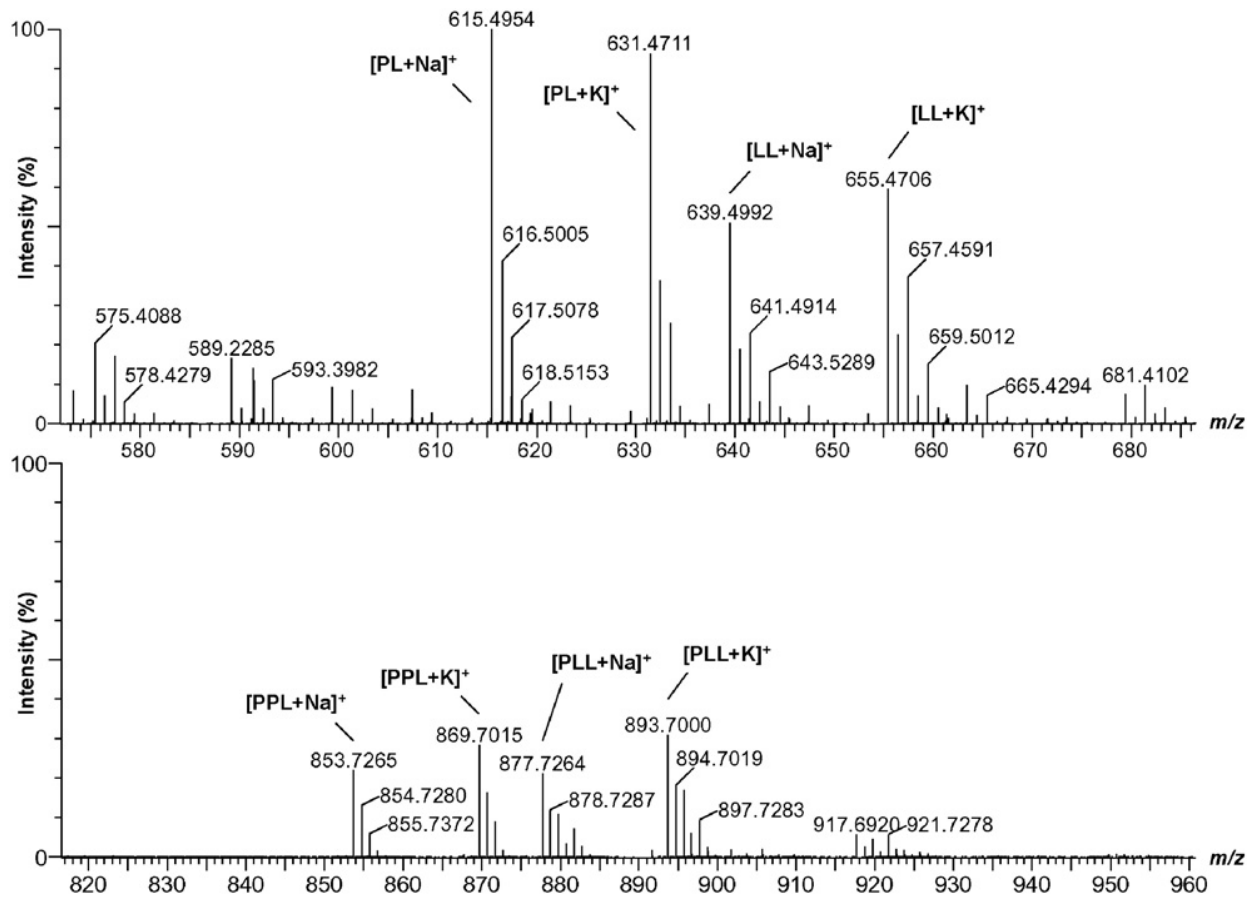

Fig. 9. ESI-QTOF zoom at scans of the acylglycerol region: diacylglycerols ( $m / z$ 600-700) and triacylglycerols $(m / z$ 800-900) from a dark roast sample. 
Table 3

Identifications suggested for the more relevant ions in the $m / z 600-800$ range.

\begin{tabular}{|c|c|c|c|c|}
\hline Experimental $m / z$ & Theoretical $m / z$ & Error (ppm) & Molecular formula & Suggested identification \\
\hline 615.4954 & 615.4964 & -1.6 & $\mathrm{C}_{37} \mathrm{H}_{68} \mathrm{O}_{5}$ & Diacylglycerols: palmitoyl-linoleoyl $(\mathrm{PL})-(\mathrm{M}+\mathrm{Na})^{+}$ \\
\hline 631.4711 & 631.4704 & 1.1 & $\mathrm{C}_{37} \mathrm{H}_{68} \mathrm{O}_{5}$ & Diacylglycerols: palmitoyl-linoleoyl (PL) $-(\mathrm{M}+\mathrm{K})^{+}$ \\
\hline 639.4992 & 639.4964 & 4.4 & $\mathrm{C}_{39} \mathrm{H}_{68} \mathrm{O}_{5}$ & Diacylglycerols: dilinoleoyl (LL) $-(\mathrm{M}+\mathrm{Na})^{+}$ \\
\hline 655.4706 & 655.4704 & 0.3 & $\mathrm{C}_{39} \mathrm{H}_{68} \mathrm{O}_{5}$ & Diacylglycerols: dilinoleoyl $(\mathrm{LL})-(\mathrm{M}+\mathrm{K})^{+}$ \\
\hline 853.7265 & 853.7261 & 0.5 & $\mathrm{C}_{53} \mathrm{H}_{98} \mathrm{O}_{6}$ & Triacylglycerols: dipalmitoyl-linoleoyl-glycerol $(\mathrm{PPL})-(\mathrm{M}+\mathrm{Na})^{+}$ \\
\hline 869.7015 & 869.7000 & 1.7 & $\mathrm{C}_{53} \mathrm{H}_{98} \mathrm{O}_{6}$ & Triacylglycerols: dipalmitoyl-linoleoyl-glycerol (PPL) $-(\mathrm{M}+\mathrm{K})^{+}$ \\
\hline 877.7264 & 877.7261 & 0.3 & $\mathrm{C}_{55} \mathrm{H}_{98} \mathrm{O}_{6}$ & Triacylglycerols: palmitoyl-dilinoleoyl-glycerol $(\mathrm{PLL})-(\mathrm{M}+\mathrm{Na})^{+}$ \\
\hline 893.7000 & 893.7000 & 1.0 & $\mathrm{C}_{55} \mathrm{H}_{98} \mathrm{O}_{6}$ & Triacylglycerols: palmitoyl-dilinoleoyl-glycerol (PLL) $-(\mathrm{M}+\mathrm{K})^{+}$ \\
\hline
\end{tabular}

the DAGs found were from the coffee matrix and not from fragmentations of TAGs from the ESI source or collision cells. Novaes, Oigman, de Souza, Rezende, and de Aquino Neto (2015) corroborate this conclusion using a high temperature gas chromatography technique coupled with a mass detector (CGHT-MS) to evaluate DAGs in coffee oil; palmitoyllinoleoyl (PL) and dilinoleoyl (LL) were the major peaks founded.

Toci, Neto, Torres, and Farah (2013), however, discussed TAG hydrolyses of diacylglycerols (and also monoacylglycerols) during storage of roasted coffees. Therefore, the origin of the DAGs founded in QTOF screening may also be due to TAG decomposition in the coffee matrix. Although some studies have shown that the position of the acyl groups on TAG affects their hydrolysis (Christie, 2011; Michalski et al., 2013), the thermal effects in this study seems to be responsible for the presence of the TAGs and DAGs, because they appear mainly in medium to very dark roasts in samples studied, probably due to the collapse of vegetable cells and the release of lipids onto the bean surface.

\section{Conclusions}

The use of the direct desorption/ionization EASI-MS ambient technique offers a promising and relatively simple protocol to determine the degree of roast and thus contribute to the reproducibility and consistency of this complex unitary operation which is coffee roasting.

As a non-target study, not all ions monitored could be identified, especially those in roasting fingerprinting by EASI-MS. However, the screenings via ESI-QTOF and HPLC-fluorescence/HPLC-PDA supplemented information, providing identity for the most relevant ions found in both mass spectrometry techniques employed.

As a study focused on non-volatiles the aim was to complement the large number of data available in the literature on the volatile composition of roasted coffee, which is highly dependent on low molecular weight constituents with selective and intrinsic procedures of extraction. Here, we could see the great contribution of the heaviest constituents present in the coffee bean to differentiate between the degrees of roasting most commonly used in coffee market.

In the samples studied, the $N$-alkanoyl-5-hydroxytryptamides were seen as chemical markers for a light roast and that the presence of diacylglycerols and triacylglycerols (higher MW species) can a dark to a very dark roast.

\section{Appendix A. Supplementary data}

Supplementary data to this article can be found online at http://dx. doi.org/10.1016/j.foodres.2016.03.021.

\section{References}

Amorim, A. C. L., Hovell, A. M. C., Pinto, A. C., Eberlin, M. N., Arruda, N. P., Pereira, E. J., \& Rezende, C. M. (2009). Green and roasted arabica coffees differentiated by ripeness, process and cup quality via electrospray ionization mass spectrometry fingerprinting. Journal of the Brazilian Chemical Society, 20(2), 313-321.

Bosco, M., Toffanin, R., Palo, D. d., Zatti, L., \& Segre, A. (1999). High-resolution 1H NMR investigation of coffee. Journal of the Science of Food and Agriculture, 79(6), 869-878.

Bottazzi, D., Farina, S., Milani, M., \& Montorsi, L. (2012). A numerical approach for the analysis of the coffee roasting process. Journal of Food Engineering, 112(3), 243-252.
Buchmann, S., Zahm, A., Kölling-Speer, I., \& Speer, K. (2009). Lipids in coffee brews-Impact of grind size, water temperature, and coffee/water ratio on cafestol and the carboxylic acid-5-hydroxytryptamides. Paper presented at the Euro Food Chemistry XV, Copenhagen, Denmark.

Chattopadhyay, A., Rukmini, R., \& Mukherjee, S. (1996). Photophysics of a neurotransmitter: Ionization and spectroscopic properties of serotonin. Biophysical Journal, 71(4) 1952-1960.

Christie, W. W. (2011). Triacylglycerols (triglycerides) part 1. Composition retrieved August 2015, from http://lipidlibrary.aocs.org/content.cfm?ItemNumber $=39366$

Chu, Y. -F. (2012). Coffee: Emerging health effects and disease prevention. vol. 59, John Wiley \& Sons.

Cody, R. B., Laramée, J. A., \& Durst, H. D. (2005). Versatile new ion source for the analysis of materials in open air under ambient conditions. Analytical Chemistry, 77(8) 2297-2302.

Cooks, R. G., Ouyang, Z., Takats, Z., \& Wiseman, J. M. (2006). Ambient mass spectrometry. Science, 311(5767), 1566-1570.

Couch, M., \& Williams, C. (1972). Mass spectrometry of tryptamines and acetylated tryptamine derivatives. Analytical Biochemistry, 50(2), 612-622.

Dórea, J. G., \& da Costa, T. H. M. (2005). Is coffee a functional food? British Journal of Nutrition, 93(06), 773-782.

Ellis, S. R., Brown, S. H., in het Panhuis, M., Blanksby, S. J., \& Mitchell, T. W. (2013). Surface analysis of lipids by mass spectrometry: More than just imaging. Progress in Lipid Research, 52(4), 329-353.

Esquivel, P., \& Jiménez, V. M. (2012). Functional properties of coffee and coffee byproducts. Food Research International, 46(2), 488-495.

Farah, A. (2012). Coffee constituents. Coffee: Emerging health effects and disease prevention 59.

Garrett, R., Schwab, N. V., Cabral, E. C., Henrique, B. V., Ifa, D. R., Eberlin, M. N., \& Rezende C. M. (2014). Ambient mass spectrometry employed for direct analysis of intact arabica coffee beans. Journal of the Brazilian Chemical Society, 25(7), 1172-1177.

Haddad, R., Sparrapan, R., \& Eberlin, M. N. (2006). Desorption sonic spray ionization for (high) voltage-free ambient mass spectrometry. Rapid Communications in Mass Spectrometry, 20(19), 2901-2905.

Harris, G. A., Galhena, A. S., \& Fernandez, F. M. (2011). Ambient sampling/ionization mass spectrometry: Applications and current trends. Analytical Chemistry, 83(12), 4508-4538.

Hertz-Schünemann, R., Dorfner, R., Yeretzian, C., Streibel, T., \& Zimmermann, R. (2013). Online process monitoring of coffee roasting by resonant laser ionisation time-of-flight mass spectrometry: Bridging the gap from industrial batch roasting to flavour formation inside an individual coffee bean. Journal of Mass Spectrometry, 48(12), 1253-1265.

Huang, M. -Z., Cheng, S. -C., Cho, Y. -T., \& Shiea, J. (2011). Ambient ionization mass spectrometry: A tutorial. Analytica Chimica Acta, 702(1), 1-15. http://dx.doi.org/10.1016/j. aca.2011.06.017.

Lang, R., \& Hofmann, T. (2005). A versatile method for the quantitative determination of $\beta$ $\mathrm{N}$-alkanoyl-5-hydroxytryptamides in roasted coffee. European Food Research and Technology, 220(5-6), 638-643.

Lang, R., Bardelmeier, I., Weiss, C., Rubach, M., Somoza, V., \& Hofmann, T. (2009). Quantitation of $\beta$ N-alkanoyl-5-hydroxytryptamides in coffee by means of LC-MS/MS-SIDA and assessment of their gastric acid secretion potential using the HGT-1 cell assay. Journal of Agricultural and Food Chemistry, 58(3), 1593-1602.

Lee, K. -W., Im, J. -Y., Woo, J. -M., Grosso, H., Kim, Y. -S., Cristovao, A. C., ... Fernandez, J. R. (2013). Neuroprotective and anti-inflammatory properties of a coffee component in the MPTP model of Parkinson's disease. Neurotherapeutics, 10(1), 143-153.

Martins, A. C. C., \& Gloria, M. B. A. (2010). Changes on the levels of serotonin precursorstryptophan and 5-hydroxytryptophan-during roasting of arabica and robusta coffee. Food Chemistry, 118(3), 529-533.

Michalski, M. C., Genot, C., Gayet, C., Lopez, C., Fine, F., Joffre, F., \& Raynal-Ljutovac, K. (2013). Multiscale structures of lipids in foods as parameters affecting fatty acid bioavailability and lipid metabolism. Progress in Lipid Research, 52(4), 354-373.

Novaes, F. J. M., Oigman, S. S., de Souza, R. O. M. A., Rezende, C. M., \& de Aquino Neto, F. R (2015). New approaches on the analyses of thermolabile coffee diterpenes by gas chromatography and its relationship with cup quality. Talanta, 139, 159-166.

Rubach, M., Lang, R., Bytof, G., Stiebitz, H., Lantz, I., Hofmann, T., \& Somoza, V. (2014). A dark brown roast coffee blend is less effective at stimulating gastric acid secretion in healthy volunteers compared to a medium roast market blend. Molecular Nutrition \& Food Research, 58(6), 1370-1373.

Segall, S. D., Artz, W. E., Raslan, D. S., Jham, G. N., \& Takahashi, J. A. (2005). Triacylglycerol composition of coffee beans (Coffea canephora P.) by reversed phase highperformance liquid chromatography and positive electrospray tandem mass spectroscopy. Journal of Agricultural and Food Chemistry, 53(25), 9650-9655. 
Speer, K., \& Kölling-Speer, I. (2006). The lipid fraction of the coffee bean. Brazilian Journal of Plant Physiology, 18(1), 201-216.

Toci, A. T., Neto, V. J., Torres, A. G., \& Farah, A. (2013). Changes in triacylglycerols and free fatty acids composition during storage of roasted coffee. LWT-Food Science and Technology, 50(2), 581-590.

Wang, X., \& Lim, L. -T. (2015). Corrigendum to "Effect of roasting conditions on carbon dioxide degassing behavior in coffee". Food Research International, 69, 434.

Wieland, F., Gloess, A. N., Keller, M., Wetzel, A., Schenker, S., \& Yeretzian, C. (2012). Online monitoring of coffee roasting by proton transfer reaction time-of-flight mass spectrometry (PTR-ToF-MS): Towards a real-time process control for a consistent roast profile. Analytical and Bioanalytical Chemistry, 402(8), 2531-2543.

Zahm, A., \& Speer, K. (2009). Degradation products of carboxylic acid-5hydroxytryptamides (C-5-HT). Paper presented at the 22nd International Conference on Coffee Science, ASIC 2008, Campinas, SP, Brazil, 14-19 September, 2008. 